\title{
Linguistic and Cultural Constraints in Vietnamese General Practitioners' Act of Initiating Clinical Information-seeking Process in First Encounters with Outpatients
}

\author{
Pham Thi Hong Nhung \\ Hue University of Foreign Languages, Hue city, Vietnam
}

\begin{abstract}
Doctor-patient communication is crucial in medical care as it is the significant instrument by which information influential to doctor's decisions of patients' health condition, their treatment plan or further examinations is provided and exchanged. While extensive studies on doctor-patient interaction in Western cultures have been made from both medical and linguistic perspective and communication is culturally conditioned across languages and cultures, little research has examined doctor-patient communication in Southeast Asian contexts. This article reports the result of a study on Vietnamese general practitioners' act of initiating information-seeking process in initial encounters with outpatients. Attempts have been made to understand Vietnamese general practitioners' choice of utterances in this process from an interdisciplinary perspective. The findings suggest a need to integrate both linguistic and cultural knowledge into the communication skills training for medical students and further research on health communication from a multi-disciplinary perspective.
\end{abstract}

Index Terms - doctor-patient communication, speech act, culture, language

\section{INTRODUCTION}

\section{A. Doctor-patient Communication}

It is widely believed that effective doctor-patient communication is "the main ingredient in medical care" (Ong, De Haes, Hoos, Lammes, 1995, p. 903), the central clinical function by which doctors and patients exchange information (Skopek, 1979; Street, 1991; Roter \& Hall, 1992) for the optimal goal of improving patients' health and medical care. Effective doctor-patient communication is a source of support, motivation, re-assurance and incentive, which then reinforces patients' self-confidence and positive view of their medical situation, and hence influences patients' health outcomes (Kaplan, Greenfield \& Ware, 1989).

From a pragmatic perspective, doctor-patient communication is categorized as institutional talk where nature of communication is strongly influenced by the characteristics of clinical contexts. Being "the heart and art of medicine" (Ha, Anat \& Longnecker, 2010, p. 38), it is one of the most complex communications as it involves interaction between individuals of non-equal positions about issues of great significance (Chaitchik, Kreiler, Shaked, Schwartz, \& Rosin, 1992; Watson, \& Gallois, 2002; Ha, Anat \& Longnecker, 2010).

Three different purposes of doctor-patient communication are identified: creating a good inter-personal relationship, facilitating exchange of information and involving patients in treatment decision making process (Ha, Anat \& Longnecker, 2010) among which creating a good inter-personal relationship is viewed as a prerequisite for optimal health care (Ong et al., 1995, p.904). Doctor-patient communication helps build mutual trust between doctors and patients (Irwin, McClelland, Love, 1989) and enables patients to express all their reasons for coming, impart information about their symptoms, feelings, thought, needs, perceptions and expectations (Weston, Brown, \& Stewart, 1989).

Exchange information involves information seeking and information giving. Doctors needs information from the patient to facilitate accurate diagnosis and establish the right treatment plan while patients have two basic needs when coming to see the doctor: the need to know and understand what the matter is (i.e., cure) and the need to feel known (listened to) and understood (i.e., care) (Ong et al., 1995). However, research has shown that physicians and doctors seem to underestimate the patient' desire for information and explanations (e.g., Chait et al., 1992), overestimate their communication skills (Tongue, Epps \& Forese, 2005) and that patients are not satisfied with doctor communication while doctors consider communication satisfactory or excellent (Stewart, 1995). More linguistics research has begun to give voice to patients from a linguistic perspective (e.g., Watson \& Gallois, 2002; Connor et al., 2012). Studies have also shown that most complaints by patients about doctors are about the issues of communication, not the issues of doctors' medical competence or clinical competency (e.g., Tongue, Epps \& Forese, 2005; Clack, Allen, Cooper \& Head, 2004; Claramita, Utarini, Soebono, Van Dalen \& Vleuten, 2013). 


\section{B. Doctors' Act of Initiating Information Seeking Process from a Pragmatic Perspective}

\section{Pre-suppositions}

In pragmatics, presuppositions refer the pre-assumptions that the speaker holds before making an utterance. For instance, the utterance "What are you going to give Mary and John for their wedding?" contains several presuppositions. Before making that utterance, the speaker has at least the following major presuppositions:

a) A person called Mary and a person called John exist.

b) These two people are going to get married.

c) People often give newly wed couples presents.

d) The listener of this utterance is going to give these 2 people a present for their wedding.

Yule (1996) lists 6 main types of pre-suppositions:

- Existential presupposition: pre-assumptions of the existence as can be seen in a) of the example above;

- Factive presupposition: pre-assumption of something as facts. For example, the utterance "I'm glad Kate passed the test" shows the speaker's takes the proposition of Kate having passed the test as a fact);

- Lexical presupposition: pre-assumptions associated with the use of certain vocabulary. For instance, the use of "stopped" in "Peter stopped smoking" shows that the speaker assumes that the person called Peter used to smoke or the presupposition b) in the example above comes from the use of the word "wedding);

- Non-factive presupposition: pre-suppositions that something is not true, not a fact. The utterance "They wish they were rich" shows the speaker's prior-to-utterance assumption that the people mentioned are not rich);

- Counter-factual presupposition: presuppositions that something is not only not true but contra to the truth. The utterance "She pretended to be sick" indicates the speaker's assumption that the person mentioned was not just not sick but actually very healthy;

- Structural presuppositions: prior-to-utterance assumptions inferred from the use of certain structures. For instance, the use of "what" in "What are you going to give Mary and John for their wedding?" shows the already assumption that the listener will give Mary and John something.

The use of pre-suppositions is helpful in understanding what people uphold to before they make an utterance and the inference of the speakers' prior-to-utterance assumptions facilitates the listener's understanding of the perspective of the speaker takes (i.e., where the utterance comes from).

\section{Doctors' major speech acts}

Austin (1962) introduced Speech act theory in which speech acts are defined as acts that are performed by means of making utterances. For instance, a person does the act of apologizing by saying "I apologize". The utterance "I apologize" then performs the function of expressing the speaker's apology, and hence is considered as a speech act. In a similar vein, "I promise" helps language users to perform the act of promising and utterances such as "Could you help me with this?" perform the act of requesting. Speech acts therefore are different from physical acts such as "swimming" or "dancing", which require physical movements of the agent.

Austin maintained that speech acts conveys 3 main forces or level of meanings: propositional/locutionary, illocutionary and perlocutionary force. Locutional force refers to the literal meaning of the utterance. Illocutionary force refers to the speaker's intended meaning by means of the utterance. Perlocutionary force is the intended impact of the utterance on the hearer of the utterance. An utterance such as "Can you close the window, Jim?" literally asks whether the listener named Jim has the ability to close the window. This is the locutionary, propositional meaning of the utterance. At illocutionary meaning, the utterance performs the act of requesting because by saying "Can you close the window, Jim?" the speaker requests the person called Jim to close the window. The perlocutionary force of the utterance is Jim's response to the utterance by standing up and closing the window.

Speech acts are often classified on the basis of their illocutionary force, which is also the focus of pragmatics, the study of meaning in context and language in use. Austin's (1962) speech act classification, extended by Searle's (1969) and modified by Cohen (1996) contains 5 categories, namely representatives, directives, expressives, comissives and declaratives.

- Representatives or assertives contain speech acts that express the belief about the world of the speaker as utterance maker. This category includes acts such as reporting or describing. When the TV presenter broadcasting live the wedding of prince Charles and Kate Middleton says "The couple are now entering the stage", s/he believes that this is what is happening.

- Directives include acts which express the speaker's desire on the listener. Typical acts of this category are requesting, ordering, commanding, and questioning.

- Expressives convey the speaker's feelings, emotion or attitudes. Complimenting, congratulating, apologizing are common acts of this category.

- Commissives refer to speech acts that reflect the speaker's intention, often towards the hearer. For instance, promising, compensating, threatening are classified as acts of commissives.

- Declaratives are speech acts aimed to change the state of the world. "I announce you husband and wife" by the judge changes the status and relationship between 2 people hearing this while "I find you guilty" by a judge could put a person in prison. 
Research in pragmatics has provided evidence that speech acts are culturally-conditioned. Just like for greeting, the English people literally ask about health: "How are you?" while the Vietnamese tend to have inquiries about food: "Have you eaten yet?" or the listener's direction of movement: "Where are you going?" (Pham, 2007).

Ong et al. (1995) review 2 main categories of utterances commonly used in doctor-patient communication, namely instrumental utterances and affective utterances (p.906). Instrumental utterances include seeking information, giving information, asking questions, giving directions, counseling (Roter, 1991), identifying and explaining treatment plan, addressing side effects of treatment (medicine or tests), discussing test results (Blanchard et al., 1983) while affective utterances mainly include showing approval, showing empathy, encouraging, introducing self to the patient, complimenting patients and so on. In other words, viewing from Speech acts theory, directives and expressives are most commonly used speech acts by doctors in communication with patients.

Viewing from Brown and Levinson's (1987) Western model of politeness where the degree of politeness is considered to correlate with the speaker's effort to reduce imposition in communication, there has been an emphasis that since at medical schools, doctor students are trained to use open-ended questions at the beginning of interviews with patients to elicit information from the patient and in medical encounters doctors need to undertake politeness strategies reduce the level of imposition and criticism (Robins \& Wolf, 1988). Since very early it has been observed in Western medical practice that doctors use negative politeness strategies (i.e., the choice of speech acts to reduce the level of imposition) by means of indirectness and various tentative formulations to soften requests and questioning (Aronsson \& Satterlund-Larsson, 1987). For instance, "You could perhaps undress a little and get on the couch and then we'll examine your thighs while I try to get hold of a report" (Aronsson \& Satterlund-Larsson, 1987, p. 8) is more likely to be used than an utterance with a high degree of directness such as "Undress and get on the couch...".

Recently, Claramita, Van Dalen, Vleuten's (2011) research on doctor-patient communication in Indonesia adds more to the growing body of literature, which suggests that doctor-patient communication in Southeast Asia is unidirectional regardless of patients' educational background, with doctors being perceived to be at a higher hierarchical level, being clearly in charge while patients are to respond and agree. In Southeast Asian settings, doctor-patient communication is affected most strongly by social distance and closeness of relationship (Claramita, Utarini, Soebono, Van Dalen, Vleuten, 2013).

\section{Health communication as institutional talk}

The interpretation of utterance meaning and of the degree of politeness is also strongly influenced by the context in which utterances are made. An utterance such as "Where is the burger sitting?" makes perfect sense in a fast food restaurant (i.e., to ask about the location of the customer who has ordered the burger) but it may not make sense outside this context. The recognition that in certain occupational contexts such as courtroom, police station, classroom and hospital the interpretation of meaning of an utterance depends greatly on how much contextual knowledge we have is represented in the concept of institutional talk in pragmatics. Often out of awareness, individuals engaged in communication are constrained by norms of institutional settings. That is in everyday communication the talk and interactions are constrained by the norms practised in or by institutional norms.

Literature (e.g., Yang, 2009) has identified 5 main strategies associated with institutional talk. These are person reference, turn-taking, lexical choice, grammatical forms, and institutionally specific inferences associated with institutional talk. In terms of person reference, a policeman may refer to himself as "we" instead of "I" to exhibit orientation towards his institutional identity. Turn-taking in institutional talk is primarily decided by the intermediate communicative role assigned with each participant. Participants decide their contribution to a conversation according to their perceptions of the institutional norms. Similarly, speakers' choice of grammatical structures, vocabulary and inferences is also influenced by their awareness of the intermediate institutional norms. In this sense, doctor-patient communication is viewed as institutional talk. As such, doctors' speech acts which are aimed to seek clinical information about the patient's health or to provide consultation for patients about their health are also influenced by the culture of the clinical context.

\section{Doctors' act of initiating information seeking process}

Doctors' act of initiating information seeking process is the speech act made by the doctor very early in his/her communication with the patient to initiate the clinical information exchange process, to ask for the reason why the patient is coming. This act often takes place right after the greeting act is made (for returning patients) or right after the introduction stage is completed (often in first encounters between patients and the doctor) and just before patients start to explain why they come in. In light of Speech Act theory, doctors' act of initiating information seeking process with patients in first encounters is characterized as a speech act of directives where the doctor initiate the process of information exchange for the sake of patients' health. This is also referred to as the act of opening medical questions, the initial solicitation of the health problem (Stivers, 2001).

As part of the doctor-patient information exchange process, the doctor's act of initiating this process is important as it does not only provide patients opportunity to inform the doctor of their health condition but also in very first encounters with outpatients, this act by the general practitioner is crucial in establishing a positive initial impression on the patient, form an opinion on the general practitioner by the patient and a neutral but friendly environment where the patient feels free to describe their medical situation. Health communication skills training for medical students in the Western cultures has emphasized the significance of using questions free of pre-judgments including moral judgment in doctor- 
patient communication. Open-ended questions like "How can I help you?" or "What brought you here?" reduce the level of imposition and encourage the patient to talk more. Using neutral, unbiased, imposition-free open-ended questions becomes a norm as they allow patients to explain, describe their health status and how they feel in their own words and help doctors obtain more information than closed questions (Murthy, 2014).

While there is much research on doctor- especially general practitioner-patient communication across Western medical settings, research on general practitioner-patient communication in Asian, particularly South East Asian medical setting is under-represented. This study aims at investigating the Vietnamese general practitioners' act of initiating clinical information seeking process in first encounters with outpatients as an attempt to provide more understanding of medical communication practice in Asia.

\section{RESEARCH}

\section{A. Research Questions}

This study is to answer 2 questions:

Question 1: How do Vietnamese general practitioners initiate information seeking process in first encounters with outpatients?

Question 2: How can Vietnamese general practitioners' act of initiating information seeking process in first encounters with patients be understood from a linguistic and cultural perspective?

\section{B. Research Methods and Participants}

The context in which data were collected is a general hospital in the central area of Vietnam. Initial encounters between 6 general practitioner s and 118 outpatients were taped recorded. Seventy-eight patients are male and 40 are female. The patients come from different educational and socio-economic backgrounds. Among 6 general practitioners, 2 are female and 4 are male. Their age range is from 32 to 49 . The participants were informed that the purpose of the study and of the recording was to look at the use of language in medical setting and interaction between general practitioners and patients. One hundred and eighteen initial encounters between patients and general practitioners were recorded.

Recordings are from 5 to 17 minutes in length. The average length is 9 minutes per recording. During the data collection process, recorded data are transcribed from the beginning of the conversation to the patient's first response to the general practitioners' act of initiating information seeking process. The rest of each conversation is not transcribed but referred to whenever necessary for a better understanding of the general practitioner-patient communication. Follow-up interviews with general practitioners were also implemented to seek further understanding of the general practitioners' acts of initiating the information seeking process with patients in special cases where the transcription of from recorded encounters alone cannot allow a thorough understanding of the act. Totally, all 6 general practitioners were interviewed for further explanation of their act of initiating the process of seeking information about patients' health in 34 out of 118 encounters.

\section{FINDINGS AND DISCUSSIONS}

The data show that the most common stage for general practitioners' act of initiating clinical information seeking process between general practitioners and patients in their first encounters right after the step of greeting and /or clarifying personal information. The most frequently recorded pattern is greeting / clarifying personal information (name, age and address) - initiating clinical information exchange process.

Typical greeting is undertaken by either the general practitioner's inviting the patient to sit down and/or to doublechecking the patient's name using a rhetorical question:

$\begin{array}{llll}\text { GP: } & \begin{array}{l}\text { Mời } \\ \text { invite } \\ \text { Please take a seat. }\end{array} & \text { bác } & \text { you (addr. term) } \\ \text { or } & \text { Anồi. } & \\ \text { seat }\end{array}$

The general practitioners investigated did not introduce themselves to the patient, except in two encounters. This could be explained by the fact that in South East Asian medical contexts, doctors often face with heavy workload and patients just turn up without prior notice or appointments.

From literal / locutional level, the act of initiating the process of seeing medical information is performed following 5 most frequent patterns.

Pattern 1: The general practitioner directly asks about the patient's pain / illness.

Example: 


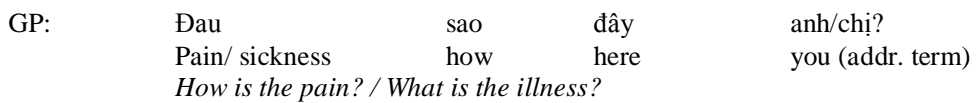

Pattern 2: The general practitioner asks about the patient's issue.

Example:

\begin{tabular}{|c|c|c|c|}
\hline GP: & $\begin{array}{ll}\text { Có } & \text { chuyện } \\
\text { there } & \text { matter }\end{array}$ & $\begin{array}{l}\text { gì } \\
\text { what }\end{array}$ & $\begin{array}{l}\text { bác? } \\
\text { you (addr.term) }\end{array}$ \\
\hline
\end{tabular}

Pattern 3: The general practitioner asks what brought the patient in or why the patient came in.

Example:

$\begin{array}{llll}\text { GP: } & \text { Sao } & \text { anh/chi } & \text { đến }\end{array}$

Pattern 4: The general practitioner asks how he/she can help.

Example:

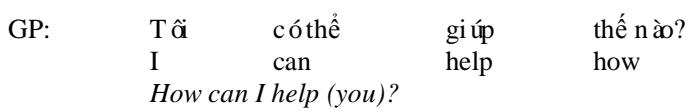

Among these 4 patterns, pattern 1 is most frequently used with 68 times out of 118 general practitioner-patient encounters, followed by pattern 2 (29 times) and then pattern 3 (16 times) and 4 (5 times).

At a glance, all utterances made by the investigated general practitioners to initiate the process of seeking medical information of the patients are open-ended questions. However, standard, neutral open-ended questions which are norm in the Western medical practice such as "How can I help you?" or "What bring you in/here?" are used at the lowest level of frequency, $17.8 \%$, with 21 times in 118 encounters.

The most common pattern of the general practitioner's act of initiating the process of eliciting information about the patient's health involves the general practitioner's direct reference to the patient's pain and/or illness. All recorded utterances of this pattern contain the lexical unit of "đau" in the Vietnamese language, which generally means pain. Typical utterances involving "đau" used by the general practitioners are as follows:

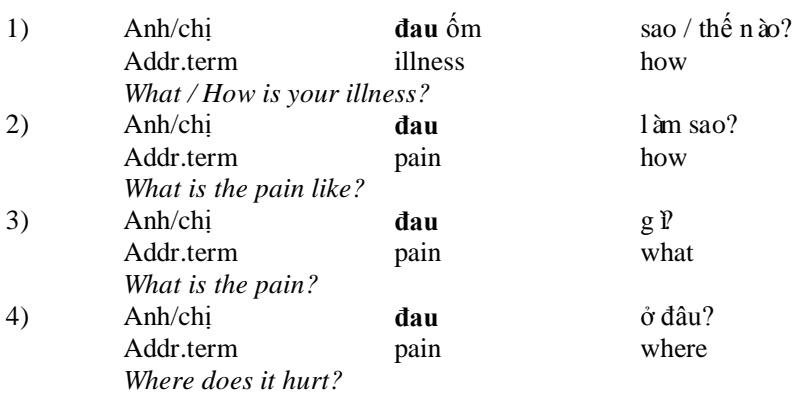

"Đau" can refer to physical pain or mental pain and its meaning can be ambiguous. For instance, when preceding or following "ốm", "đau" (“đau ôm" or "ốm đau") just means illness or sickness, as seen in example 1). When not used with "ốm", "đau" can convey all the senses from pain / painful, ill / illness, sick / sickness, ache /aching to being hurt as illustrated examples from 5) to 8) below.

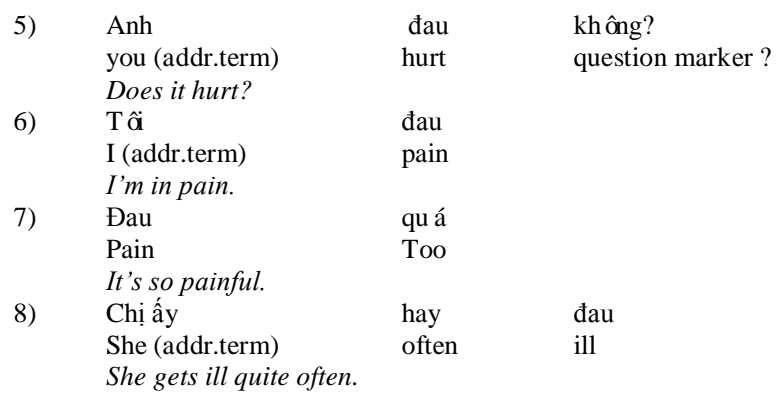

All of the utterances containing "đau" are open-ended questions which convey the general practitioners' presupposition of the existence of pain or illness of some kind on the patient (i.e. existential presupposition). In other 
words, this suggests the Vietnamese general practitioners' pre-assumptions that some type of pain exists within the patient and this is why patients came to see a doctor.

While "the social, economic and psychological costs of pain worldwide are immeasurable" (Wierzbicka, 2013, p. 307), "pain is now deemed to be the most common reason why people seek medical care" and becomes the "fifth vital sign" to be assessed apart from pulse, blood pressure, respiration, and body temperature (Fernandez \& Wasan, 2010 , p. 450). However, this does not mean that pain is the only and primary reasons why people come to see a doctor. In addition, it is important to identify pain across cultures because what it means may vary in different cultures and language. For instance, in Russian there is no distinction between ache and pain as the noun bol and the verb bolit cover both aspects of meaning, and so definition about pain needs to be based on empirical evidence in cross-linguistic semantics (Wierzbicka 2013, p. 308).

Interview data with the 6 general practitioners about their frequent use of the word "đau" in their initial encounters with patients show that the general practitioner employed "đau" in their questions to refer to the reasons why the patient comes, the symptoms on the part of the patients, the general health condition of the patient rather than just physical pain. However, as said elsewhere the meaning of "đau" varies from general illness to a specific physical pain and the linguistic constraint of the word (i.e. its ambiguity) does not always help ensure that patients' interpretation of "đau" in the general practitioners' question is the same as it is intended.

On the other hand, interview data also show that all 6 general practitioners believe that physical pain is the most common reason why patients come to see them, and they suffer from a lack of time due to heavy patient load, so in many cases it saves time to directly ask the patients to describe their pain if any. This is understandable from a sociocultural perspective. Living in a developing country, Vietnamese do not often have the habit of having their health checked on a regular basis. It is not uncommon that they do not come to see doctors even when they notice unusual symptoms. They can get to a pharmacist and get hold of some medicine as verbally "prescribed" by the pharmacist. Others may try traditional herbal medicine. A majority of population will only come to see doctors when the symptoms do not reduce or already lead to consequences. Most of theses cases are associated with pain. To add to general practitioners' workload, patients do not and are not asked to make an appointment to see a doctor or a general practitioner. They just turn up when they want to.

The study has shown the cultural and linguistic constraints on the Vietnamese general practitioners' act of initiating clinical information-seeking process. It also shows that the Vietnamese general practitioner's lexical choice in the case of "pain" is closely associated with clinical setting as context of institutional talk.

\section{CONCLUSION}

Doctors in a unique position of respect and power (Ha, Anat \& Longnecker, 2013). Research has provided empirical evidence that doctor's choice of language have impact on patients' beliefs of their health status (e.g., Tayler \& Ogden, 2005; Tailor \& Ogden, 2009). In a Southeast Asian Confucian context like Vietnam, doctors are considered even in much higher hierarchical level in comparison with patients who are to listen more than ask question or argue. Patients can come to see a doctor for many reasons, not just due to pain and so doctors' act of initiating information seeing process in initial encounters with patients under the influence of linguistic and cultural constraints as shown in this study may mislead patients by making the patients think that the doctor has already pre-supposed about them having pain, which then may affect the patients' feelings and thought of their health condition, influencing the information they provide the doctor, preventing the doctor from obtaining reliable, unbiased information about patients' medical condition. This could consequentially influence the doctor' conclusions and decisions regarding patients' health. Given that doctors and patients may not perceive the word "đau" in doctors' act of initiating clinical information-seeking process the same, the current study also suggests a need to investigate whether there is a consensus between doctors' and patients' perceptions of ambiguous institutional vocabulary.

\section{ACKNOWLEDGMENT}

The author wishes to thank anonymous medical administrative staff members who have provided favourable conditions for her data collection process.

\section{REFERENCES}

[1] Aronsson, K. \& U. Satterlund-Larsson. (1987). Politeness strategies and doctor-patient communication. On the social choreography of collaborative thinking. Journal of Language and Social Psychology 6.1, 1-27.

[2] Austin, J. L. (1962). How to do things with words. Oxford: Oxford University Press.

[3] Blanchard, C. D. \& J. C. Ruckdeschel, E. B. Blanchard \& J. G. Arena, N. L. Saunders \& E. D. Malloy. (1983). Interactions between oncologists and patients during rounds. Annual International Med 99, 694-699.

[4] Brown, P. \& S. Levinson. (1987). Politeness. Cambridge: Cambridge University Press.

[5] Chaitchik, S., S. Kreitler, S. Shaked, I. Schwartz \& R. Rosin. (1992). Doctor and patient communication in a cancer ward. Journal of Cancer Education 7.41, 41-54.

[6] Clack, G. B., J. Allen, D. Cooper, J. O. Head. (2004). Personality differences between doctors and their patients: Implications for the teaching of communication skills. Med Educ 38.2, 177-186. 
[7] Claramita, M., J. V. Dalen, \& C. V. der Vleuten. (2011). Doctors in a Southeast Asian country communicate sub-optimally regardless of patients' educational background. Patient Education and Counseling 85, 169-174.

[8] Claramita, M., A. Utarini, H. Soebono, J. V. Dalen, J. \& C. V. der Vleuten. (2013). Doctor-patient communication in a Southeast Asian setting: The conflict between ideal and reality. Adv. Health Sci Educ 16.1, 69-80.

[9] Cohen, A. (1996). Speech acts. In S. L. McKay \& N. H. Hornberger (Eds.), Sociolinguistics and language teaching (pp.383420). Cambridge: Cambridge University Press.

[10] Connor, U., M. Anton, E. Goering, K. Lauten, A. Hayat, P. Roach \& S. Barlunda. (2012). Listening to patients' voice: Linguistic indicators related to diabetes self-management. Communication \& Medicine 9.1, 1-12.

[11] Fernandez, E. \& A. Wasan. (2010). The anger of pain sufferers: Attributions to agents and appraisals of wrongdoings. In M. Potegal, G. Stemmber \& C. Spielberger. (Eds.), A handbook of anger (pp. 449-464). New York: Springer.

[12] Ha, J. F. \& D. S. Anat \& N. Longnecker. (2010). Doctor-patient communication: A review. The Ochsner Journal 10, 38-43.

[13] Irwin, W. G., R. McClelland \& A. H. G. Love. (1989). Communicating skills training for medical students: An integrated approach. Medical Education 23, 387-394.

[14] Kaplan, S. H., S. Greenfield \& J. E. J. Ware. (1989). Assessing the effects of physician-patient interactions on the outcomes of chronic disease. Med Care 27, S110-S127.

[15] Murthy, K. (2014). Doctor patient communication. Web http://www.indiandoctors.com/paper/157.php3 (accessed 13/5/2013).

[16] Ong, L. M. L., J. C. J. De Haes, A. M. Hoos \& F. B. Lammes. (1995). Doctor-patient communication: A review of the literature Social Science of Medicine. 40.7, 903-918.

[17] Robins, L., Wolf, F. M. (1988). Confrontation and politeness strategies in physician-patient interactions. Soc. Sci. Med 27.3, 217-221.

[18] Roter, D. L. \& J. A. Hall. (1992). Doctors talking with patients, patients talking with doctors. Auburn House, Westport, CT.

[19] Roter, D. L. (1991). The Roter method of interaction process analysis. RIAS Manual. Baltimore, MD: Johns Hopkins University Press.

[20] Roter, D. L., J. A. Hall \& N. R. Katz. (1987). Relations between physicians' behaviors and analogue patients' satisfaction, recall, and impressions. Medical Care 25, 437-451.

[21] Searle, J. (1969). Speech acts: An essay in the philosophy of language. Cambridge: Cambridge University Press.

[22] Skopek, L. (1979). Doctor-patient conversation: A way of analyzing its linguistic problems. Semiotica 28.3-4, 301-311.

[23] Stewart, M. A. (1995). Effective physician-patient communication and health outcomes: A review. CMAJ 152.9, $1423-1433$.

[24] Stivers, T. (2001). Negotiating who presents the problem: Next speaker selection in pediatric encounters. Journal of Communication 51.2, 1-31.

[25] Street, R. L. (1991). Information-giving in medical consultations: The influence of patients' communication styles and personal characteristics. Social Science of Medicine 32.541, 541-548.

[26] Tailor, A. \& J. Ogden. (2009). Avoiding the term 'obesity': An experimental study of the impact of doctors' language on patients' beliefs. Patient Education and Couseling 76.2, 260-264.

[27] Tayler, M. \& J. Ogden. (2005). Doctors' use of euphemisms and their impact on patients' beliefs about health: An experimental study of heart failure. Patient Education and Counseling 57, 321-326.

[28] Tongue, J. R., H. R. Epps \& L. L. Forese. (2005). Communication skills for patient-centered care: Research-based, easily learned techniques for medical interviews that benefit orthopaedic surgeons and their patients. J. Bone Joint Surg Am 87, 652658.

[29] Watson, B. \& C. Gallois. (2002). Patients' interactions with health providers: A Linguistic Category Model approach. Journal of Language and Social Psychology 21.1, 32-52.

[30] Weston, W. W., J. B. Brown \& M. A. Stewart. (1989). Patient-centered interviewing - Part 1: Understanding patients' experiences. Can Family Physician 35, 147-151.

[31] Wierzbicka, A. (2009). Language and metalanguage: Key issues in emotion research. Emotion Review 1.1, 3-14.

[32] Wierzbicka, A. (2013). Is pain a human universal? A cross-linguistic and cross-cultural perspective on pain. Emotion Review 4, 307-317.

[33] Yang, X. (2009). Conversation strategies in institutional dialogue. Asian Social Studies 5.7. Doi: http://ccsenet.org/journal/index.php/ass/article/view/2976/2743.

[34] Yule, G. (1996). Pragmatics. Oxford: Oxford University Press.

Pham Thi Hong Nhung obtained a Bachelor degree in English education in 1997 with Hue University of Education, an MA in 2002 and a Ph.D in 2008 in applied linguistics both with the University of Queensland, Australia.

She has been teaching pragmatics, intercultural communication, discourse analysis, applied linguistics, language testing and assessment, and TESOL methodology to postgraduate students. She is also Vice Rector of Hue University of Foreign Languages, in Hue city, Vietnam since 2009, in charge of postgraduate studies and research. Her latest book is titled Communicating with Vietnamese in intercultural context: Insights into Vietnamese values (Cantho city, National Education Publishing House, 2011). Her current research interest is applied linguistics, clinical pragmatics, in particular health communication.

Dr. Pham is a member of Vietnamese Linguistic Association. She also has membership with TESOL. She has won a number of prestigious scholarships and fellowship awards including ADS, IPRS, Endeavour scholarship (Australian awards), Lotus fellowship award (European commission) and (American) United Board Fellowship award. 